\title{
Unlocking the potential of tracking technology for co-created tourism planning and development: Insights from the Tourism Tracer Tasmania project
}

\begin{abstract}
The tourism industry and governments have typically been slow to embrace technology and data analytics as planning and development tools. The Tourism Tracer team in Tasmania, Australia, believed it could use technology to help industry and government better understand where tourists go in Tasmania and collect other information about them. From the beginning the team collaborated with industry and government in the creation of key aspects of the project, including survey questions, recruitment design, Dashboard features and functionalities and reporting. The team designed an app which collected locational and survey data from approximately 1,000 tourists. This data was then disseminated back to the community in a variety of ways including being visualised on the Tourism Tracer Tasmania Dashboard. Further specific data analytics were sought for infrastructure planning, road safety planning, and a better understanding of conversion and dispersal. With clear benefits flowing to so many stakeholders, data and analysis platforms such as Tourism Tracer should be regarded as key infrastructure which delivers 'public goods' to the tourism industry and wider community. The paper argues that while the value of technologies such as Tourism Tracer are widely recognised many governance and funding issues remain.
\end{abstract}

\section{Introduction}

Tourism and hospitality services are widely recognised as important growth sectors and are a vital source of export income across the Asia Pacific (UNWTO \& GTRC, 2016). Yet the tourism industry and governments, which support it, have been relatively slow to embrace technology and data analytics as planning and development tools (Christian, 2000; Shaffer, 
2016). Rather, the focus has been on 'smart tourism' initiatives such as accessing open data sources and the provision of free Wi-Fi (Gretzel et al 2015). Traditionally this underinvestment in tourism research and planning has been attributed to the diverse array of private operators in the sector who individually have few incentives to invest in research and technology infrastructure which benefits the industry as a whole. Given this industry structure we would expect governments and regional tourism authorities to fill the gap and provide these 'public goods', but again, governments in most jurisdictions in Australia, where this study was based, have tended to underinvest in tourism due to rivalry between industry operators and regions. Across the Asia Pacific and in Australia in particular, we are left with a reactive planning and development model which in times of high growth may threaten the long term environmental and social sustainability of the sector (Hall, 2001).

This article has two closely related objectives. First, it describes the innovative Tourism Tracer Tasmania project which demonstrates how careful collaboration between industry, government and researchers can lead to the co-creation of technology platforms and analytical tools that can greatly assist tourism planning and infrastructure development. However, as with many rich data sets and analytical tools, once established they have many unanticipated uses and therefore should be regarded as important planning infrastructure in their own right. , Secondly, the paper highlights both the many benefits of tracking technology and data analytics for tourism research, planning and market analysis while also demonstrating the governance and funding challenges associated with developing and promoting this technology so that it delivers maximum value to the industry and wider community.

The article begins with a brief overview of the origins and objectives of the Tourism Tracer Tasmania project including its commitment to industry engagement and co-design. Section 2 describes the technology and how it was applied to achieve the original project 
aims of tracking visitors' movements across an entire region and linking this back to their socio-demographic profiles. However, as the research team analysed and presented results to stakeholders it became apparent that the rich tracking data could be used to address a much wider range of academic and industry research questions from infrastructure demand, road safety challenges, land management risks and destination specific interpretation and marketing. A small sample of these unintended benefits is described in Section 3. The paper concludes by describing some of the funding and governance challenges for the ongoing sustainability of research and data services on which the future of the tourism sector depends.

\section{The origins and aims of Tourism Tracer}

Given that Tasmania, Australia's island state, is blessed with stunning temperate wilderness (approximately one fifth of the state's landmass has World Heritage status -

http://www.parks.tas.gov.au/index.aspx?base=391), numerous cultural and artistic attractions and a thriving food and wine scene there is little wonder that the state's tourism sector is booming. Latest figures show that 1,269,600 visitors travelled to Tasmania in financial year 2016-17, up from 1,068,000 in 2014. Similarly, expenditure is up, with a total spent by visitors in financial year 2016-17 of 2.26 billion, up from $\$ 1.75$ billion in 2014 (T21, 2017).

The growing importance of tourism to the Tasmanian economy, combined with the fact that visitor demographics, preferences and travel patterns are changing rapidly, provided an impetus for the creation of the Sense-T program (http://www.sense-t.org.au/). This was a government-industry-research sector collaboration focused on using digital sensing to boost innovation and productivity across a range of industry sectors. As part of its work program, Sense $-\mathrm{T}$ funded a research project that utilised sensing technology to address tourism industry research needs. A commitment to co-design was a central element of the Sense-T research program in that research questions and methods were developed jointly by industry 
and researchers. This collaboration began in 2016 and it was soon agreed that the focus would be on developing tracking methods and technologies to provide a more detailed picture about how visitors moved around Tasmania because while specific destinations had data on their customers, apart from traditional paper-based surveys, little was known about movement patterns across the state and how they changed over time and among key market segments.

Having engaged industry, the Tourism Tracer team set about applying technology to understand where exactly tourists go in Tasmania, for how long and details about who they are. In addition to this central research question, the team also aimed to generate useful and influential data and analysis for a wide range of stakeholders including government and regional tourism and marketing agencies. The project also had a strong emphasis on knowledge transfer between researchers, stakeholders and the wider community especially given tourism researcher have been accused of not being sufficiently engaged with those who should be its key stakeholders (Czernek, 2017; Walters, Burns \& Stettler, 2015; Scott \& Ding, 2008). In order to encourage input and maximise the impact of the project, the research team consulted various units and agencies of the Tasmanian Government, local council and regional tourism authorities, which could benefit. As is explained in greater detail in Section 3, it soon became apparent that data could be applied to a much wider range of planning and policy problems. These included: infrastructure investment decisions, from car parks in national parks to road upgrades; safety information, which could include more targeted messaging to particular groups identified in the data; creation of more targeted and better informed marketing campaigns and also testing the success of marketing campaigns. Secondly, given the diversity of the sector, the team was determined to provide tourism industry operators, from the largest to the smallest, with information to aid better decisionmaking and understanding of their actual and potential customers. Lastly, the team wanted to 
provide the Tasmanian community with interesting insights into how visitors travel within their state in order to enhance the relationship between the community and University of Tasmania research.

The broad aims of the research project along with its commitment to community engagement and research co-creation were clear but the greatest challenge was developing technology and research methods that would generate rich data, while addressing industry research questions. In the period from January 2016 to February 2018 approximately 1,000 tourists were tracked and surveyed.

\section{Tourism Tracer methods, analysis and insights}

Prior to the development of tracking technology, analysis of travel movement and itineraries has relied on tourists' memory and knowledge to detail where they had been. This could involve the use of trip diaries or hand-drawn maps. However, these are onerous for the participants, are subject to inaccuracies and do not provide high levels of detail (Lew and McKercher, 2006; Shoval, McKercher, Ng \& Birenboim, 2011; Thimm and Seepold, 2016; Shoval and Isaacson, 2006; Modsching et al., 2008; Beeco, Huang et al., 2013). In addition, socio-demographic information has traditionally been collected using paper-based surveys administered at the end of the trip. Again, these do not provide detailed information on where tourists actually go.

Researchers have been increasingly using GPS loggers to track movement of different groups, including the following: recreational walkers (Beeco and Hallo 2014; Hallo, Beeco, Goetcheus, McGee, McGehee and Norman, 2012); visitors to an American state (Beeco et al., 2013); visitors to a Danish island (Nielsen et al. 2010); tourists in Hong Kong (Shoval et al., 2011; skiers in ski resorts (Zillinger 2012; O’Connor et al. 2005); McKercher, Shoval, Ng and Birenboim, 2012; Grinberger, Shoval and McKercher 2014); tourists in theme parks 
(Birenboim, Anton-Clave, Russo and Shoval, 2013); tourists in Melbourne and Sydney (Edwards and Griffin 2013) and cruise ship tourists (de Cantis et al., 2016). These groups were tracked for short periods, mostly one day maximum, due to the technical difficulties posed by battery life of GPS loggers, collecting the loggers and the logistical complexity of administering the paper-based surveys (Edwards \& Griffin, 2013; Shoval et al., 2011; McKercher, et al., 2012; Grinberger et al., 2014). In some studies, such as Bauder et al.'s (2014) on tourist movement in Paris and Bauder and Freytag 's (2015) in Freiburg, the researchers detailed the potential for studies such as theirs to offer new perspectives for both tourism research and tourism destination management. Private enterprises, such as Disney and Princess Cruises, are investing in technologies that yield rich data on the behaviour of their customers. Disney has released its 'MagicBand' - a wristband device that allows its customers to enter its theme parks, open Disney Resort hotel room doors and buy food and merchandise, as well as 'unlocking' prizes and special offers (https://disneyworld.disney.go.com/en-eu/faq/bands-cards/understanding-magic-band accessed 15/6/18). These devices use short- and long-range readers and allow Disney to collect information about products and services engaged with, wait times for rides, restaurants and other attractions, and "similar" types of information ultimately leading, it is claimed, to improvements in the guest experience (https://disneyworld.disney.go.com/eneu/faq/my-disney-experience/my-magic-plus-privacy/ accessed 15/6/18). Princess Cruises also offers a smart device to its customers - the wearable Ocean Medallion. Similar to the Disney product, it is marketed as allowing users to access experiences and to open room doors (https://www.princess.com/ships-and-experience/ocean-medallion/ accessed 15/6/18). These devices interact with a number of apps which can be downloaded onto guests' devices and presumably allow Princess Cruises to track guests' movement on and off board the ship, collecting information on infrastructure used, destinations, attractions and businesses visited. 
Therefore, it is clear that tourist tracking technologies have largely been deployed in the purely academic or private enterprise space, with limited provision made for further transference to industry and government to inform decision-making, The Tourism Tracer project was designed as a result of an industry led research body and as such, the process of co-creation and knowledge transfer needed to be at the forefront of our design. Co-creation has traditionally been designed as a process of product formation that occurs between customers and an organisation. Binkhost and Dekker, 2009: 315) define it as such:

The co-creation experience results from the interaction of an individual at a specific place and time and within the context of a specific act. A real co-creation experience is neither company nor product centred.

In co-creation, customers are involved in the creation of products, rather than acting as passive recipients (Bueno \& Rameckers, 2003). This ensures that needs are met (Binkhorst and Dekker, 2009). In our case, the customer was our tourism industry, and the organisation was the University. The process of co-creation can arguably empower participants (Fuchs \& Schreier 2011; Grissemann \& Stokburger-Sauer 2012) and relies on high amounts of communication with customers (Auh, Bell, McLeod \& Shih 2007). Recently, smartphone applications have been identified as highly useful tools to assist in co-creating experiences (Wang, Li \& Li 2013; Wang, Park, \& Fesenmaier, 2011). However, at the time of the study, the research team was unable to identify similar research projects that had used co-created app-based technology in a research environment.

The Tourism Tracer team wanted to collect locational and socio-demographic data using one platform to analyse visitors' entire holidays in the island state of Tasmania. After considering all options, the team developed a tracking app which collects data points every few seconds using the Global Navigation Satellite System (GNNS) and also delivers surveys to participants. Participants were prompted to complete two surveys - the entry survey when 
the app is first activated and an exit survey which pops up on the second last day of the trip. The team considered developing a standalone app that tourists could download onto their own phones. In some previous studies tourists had seen this as too invasive and declined to take part (Thimm \& Seepold, 2016; McKercher \& Lau, 2009), although Yun and Park (2015) had some success tracking festival-goers at a five-day event in Korea via this method. Given the expectations of industry partners the Tourism Tracer team decided to adopt a resource intensive but less risky approach: project smartphones were purchased and the app was preloaded onto them. Most of the phones' functions were stripped off but SIM cards were installed providing free internet data to participants. Tourists could use these smartphones to hotspot their own personal devices. The free internet data proved to be a strong enough incentive to ensure participation, with almost 1,000 tourists tracked using this method (see Hardy, Hyslop et al. for a methodological discussion of the project). During 2016 and 2017, the research team recruited 960 free independent tourists who were in Tasmania to travel around the state. The sample included $21 \%$ international visitors and $79 \%$ domestic visitors, which was slightly higher than the 16\% / 84\% split recorded in the Tasmanian Visitor Survey (Tourism Tasmania, 2016). However, of the domestic visitors that were recruited, the percentage breakdown of tourists' home state within Australia closely reflected that recorded in the Tasmanian Visitor Survey. This period was chosen to reflect the average minimum and average maximum time that touring visitors were in the state. The team chose to focus on independent visitors who were primarily in the state to travel, in order to test both the temporal and spatial capabilities of the technology.

However, it also became apparent over the course of the project that there were motivators other than free internet data encouraging participation. These included a sense of being involved in university research that aimed to support the Tasmanian tourism industry and ultimately, enhance the visitor experience. On top of this, the app also provided another 
incentive: the very popular TourTracer map (see figure 1). On completion of the exit survey, participants received their own personalised map of their time in Tasmania, which they could share online with friends or family. These considerations, plus the desire to find a lower-cost method of data collection, led the researchers to release a downloadable app on the App and Google Stores in February 2018, that tourists could download onto their own phones. Since its release the app has been downloaded by 150 visitors per month as a result of low-key advertising in Hobart and Launceston Airports and on the Bass Strait ferry. To further enhance the attractions of the TourTracer map, users are now able to overlay their Facebook or Instagram feeds on it, allowing photos to be geo-tagged.

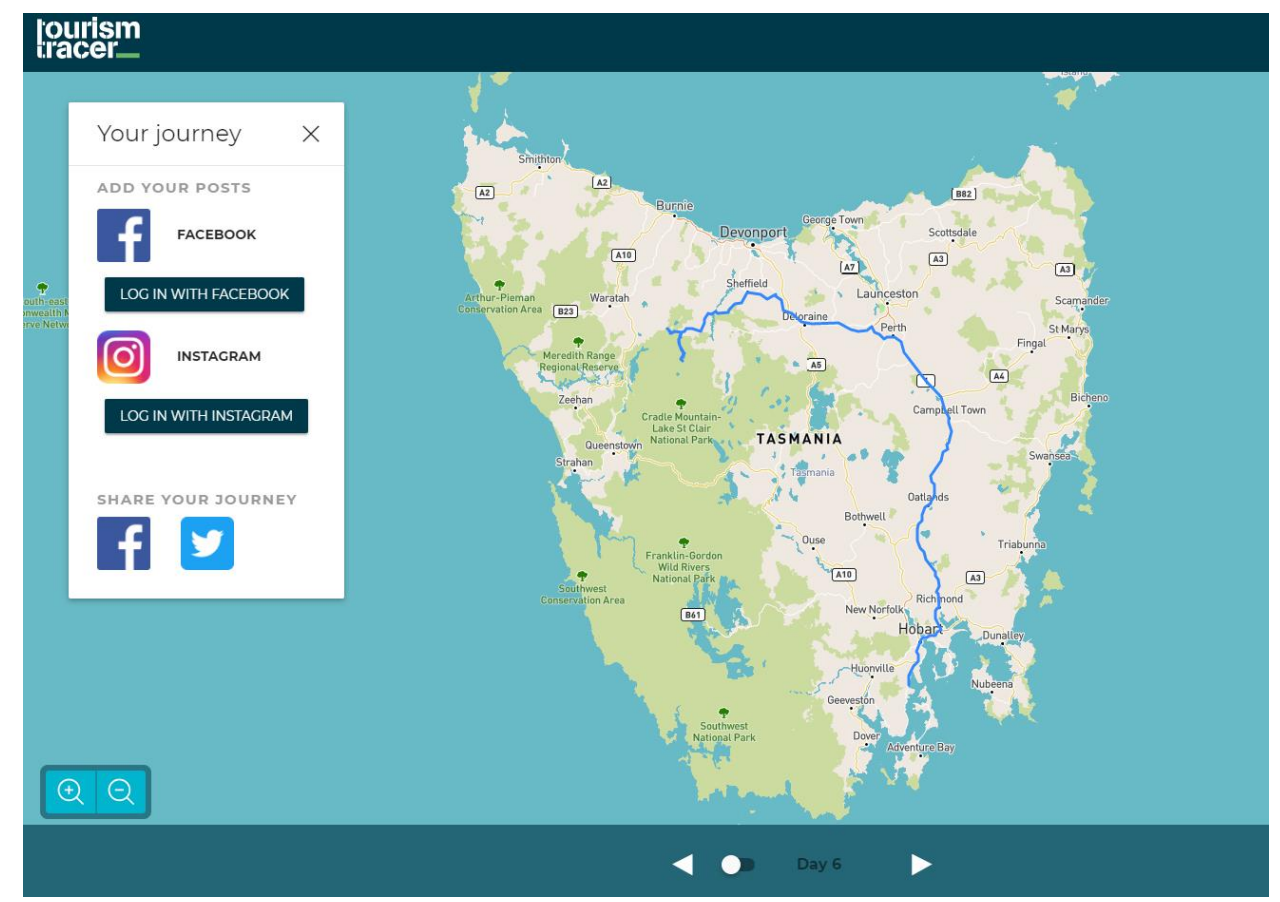

Figure 1: Example of TourTracer map

\section{Stakeholder Engagement}

In recognition of the need to make analysis and research findings more accessible to the tourism industry the research team created an interface which would do the data justice and which would provide an engaging experience for the user - the Tourism Tracer Dashboard 
(https://tasmania.tourismtracer.com/) - an online portal where interested parties can see the data visualised. Users are able to turn filters on and off and view the data in either moving visualisations or in a heat map view. Furthermore, other data sets (from the Tasmanian Visitor Survey and the Australian Tourism Data Warehouse) have been incorporated to enhance the richness of the user's experience. In the draft phase of the Dashboard, the team conducted feedback sessions with key stakeholders from government and industry. This allowed the team to refine the Dashboard and work on further improvements.

The Dashboard has a variety of features. Firstly, it shows 'Paths through the State' users can either view tourists' journeys via moving data points or in a heat map view. Filters can then be switched on or off to observe different travel patterns according to different cohorts. These include port of entry, purpose of visit, place of residence and social media used during visit.

Secondly, 'Points of Interest' integrates data from the Australian Tourism Data Warehouse. Users can click on any tourism-related business registered with the ATDW, and observe the percentage of tracked tourists who passed by this spot and where else they visited while in the state.

Lastly, users can click on 'Regions \& Trends', which offers some sophisticated analysis. Here there is a choice between Council areas, Tourism Region Authority areas or key towns. Users click on their choice and are given information on percentage of tracked tourists who spent their first night in that area, percentage of tourists who stayed overnight in that area, numbers of nights spent in that area and an hourly activity breakdown for that area.

The Tourism Tracer Dashboard is a 'living' tool: it continues to grow as data is visualised in real time. The Dashboard does what has never been done before: it shows where tourists actually go and also who they are. It goes deeper still, and shows the businesses and 
other tourism locations and who passes by; and it gives detailed analysis of the regions and towns of Tasmania.

The Dashboard is available free of charge to the public. This means that anyone who would like to understand what tourists are actually doing in Tasmania can access detailed information. Large businesses through to small-time operators, government units, tourism authorities and councils can zero in on their attraction or business to better understand their customers. They can see who these customers are and what else they do when they are in Tasmania. They can understand what social media their customers are using, whether they have been to Tasmania before and whether Tasmania is their only destination. And they can see each of these cohorts' travel routes. This understanding can support better decisionmaking around infrastructure, safety, business investment, creation and testing of marketing campaigns and co-marketing opportunities.

\section{The unanticipated planning and development dividends of tourist tracking}

The primary aim of the Tourism Tracer research project was to develop and deploy phonebased tracking technologies which would yield detailed analysis of travel movements and visitor itineraries across Tasmania. As we have noted, having conducted detailed visitor tracking it became apparent that the data collected could be analysed to address a wider range of industry research questions than originally envisaged. This clearly demonstrated the extent to which the tourism industry is interconnected and interacts with so many other sectors (Sedarati, Santoa, Pintassilgo, 2018). Specifically the research team was asked by industry partners to undertake bespoke analysis to address a series of specific research questions including: 1) infrastructure use and future demand 2) road safety and visitor driving behaviour 3) visitor conversion and 4) dispersal into regions. In this sense the Tourism Tracer dataset has some of the characteristics of a 'public good' in that once collected and analysed 
it can provide planning and other benefits to the industry and wider community well beyond those that were originally anticipated. The remainder of this section will describe some of the unintended benefits of the Tourism Tracer project prior to considering some of the governance and funding implications of the project.

\section{1) Tourism Tracer and Infrastructure Planning}

The Tourism Tracer Dashboard provided unprecedented insights into how visitors moved around the state including the demand for specific tourism infrastructure down to who is it at a particular point at particular point in time. For example, during an early industry presentation the research team linked tourist tracking data to the GPS coordinates of public

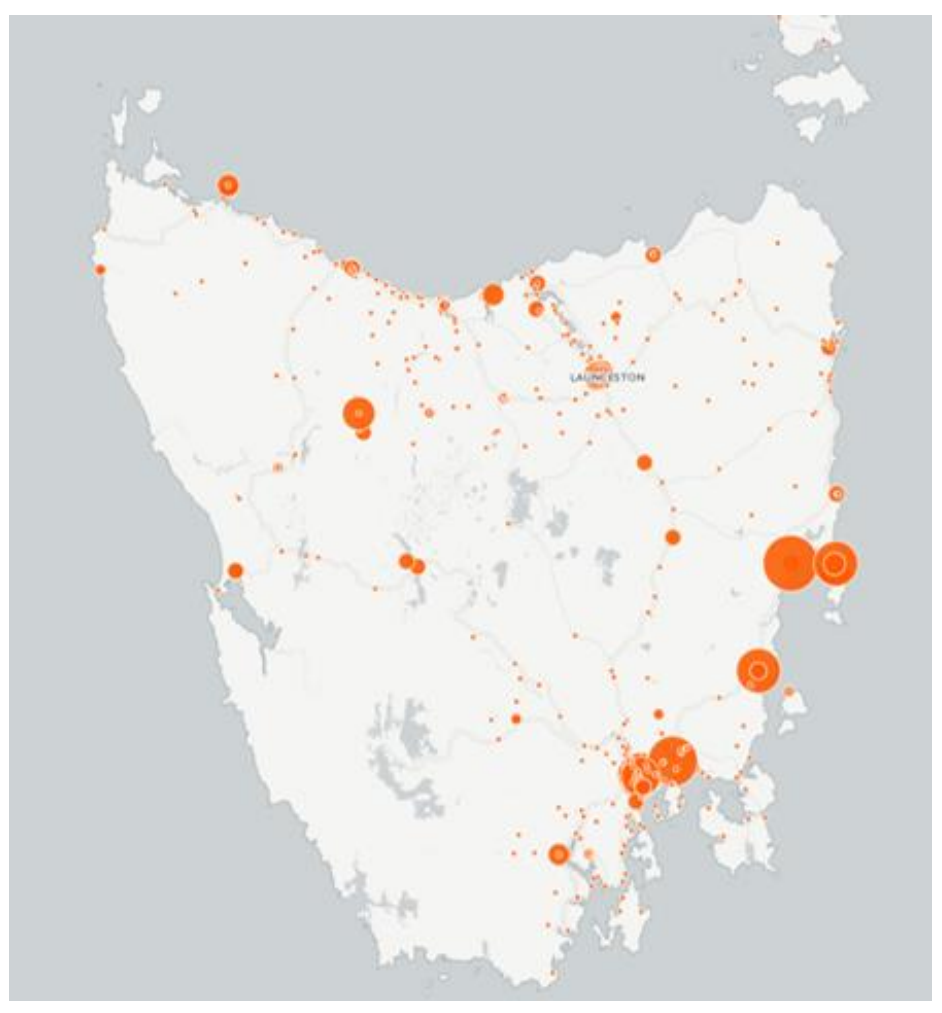

Figure 2: Visitor usage of Tasmanian public toilets

toilets in Tasmania to determine the most popular public toilet in Tasmania (see figure 2).

This highlighted how the technology could be used to predict and manage demand for tourism infrastructure. 
A specific example of bespoke analysis of the Tourism Tracer data set was a study to investigate tourist use of the Wineglass Bay Track Car Park on Tasmania's iconic Freycinet Peninsula for the Tasmanian National Parks and Wildlife Service in 2017 (Tourism Tracer 2017e). This car park experiences heavy use in peak tourist season and is often full resulting in congestion, delays and a compromised visitor experience. The study focussed on which visitors use the car park at different times of the day, how long they stay and whether they stay in the park overnight. The findings of this report were used to inform a destination management plan and were expected to also support messaging about timing of visits to Freycinet.

This research has subsequently been extended to establish how many visitors to the National Park undertake longer day walks to destinations such as the Wineglass Bay beach to assist with track management, signage and likely future infrastructure needs. These Freycinet examples are just two of many with the data also providing insights into accommodation demand and the need for caravan and RV sites and infrastructure.

\section{2) Road safety}

There is increasing recognition of the road safety issues involved in tourist visitation to Tasmania. In Australia, road accidents contribute to $14 \%$ of overseas tourists' death each year (Leggatt and Wilks, 2009). Interstate tourists to Tasmania also represent a significant concern. Between 2010 and 2014, tourists were involved in 2,010 crashes on Tasmanian roads: 77 per cent of these were interstate tourists and 23 per cent were international tourists (Department of State Growth 2015). It was recognised that the Tourism Tracer data could be used to gain insights into what could be contributing to these accidents. Analysis into tourist travel behaviour on four high-use road systems managed by the Tasmania was specially commissioned by the Road Safety Unit of the Tasmanian Department of State Growth 
(Tourism Tracer 2017a). The Tracer Team determines the average travel speed of tourists relative to the posted speed limit, road form (ie, curvature and sinuosity), and time of day. The analysis also explored the impact that place of origin and age of tourists had on travel behaviour. The assessment further examined the percentage of tourists on each road system engaged in risk-taking behaviour (travelling at $10 \mathrm{~km} / \mathrm{hr}$ above posted speed limit) and length of time spent on the road. It is expected that insights from this analysis will support decisionmaking around road infrastructure, signage and information provision. In addition, the methods of analysis developed by the team can be applied to other roads and/or time periods to provide further information and longitudinal insights, if required. Results showed that many cohorts commonly travel very long distances in one day, perhaps providing insights into the need for better and more targeted planning information and investment in more regional accommodation.

\section{3) Conversion}

The team has undertaken analysis of key towns and attractions, such as Richmond - known as Tasmania's most significant historic town (Aussie Towns 2017). This Georgian township is located approximately 27 kilometres northeast of Hobart. Analysis was undertaken of how many tourists go to Richmond, for how long, at what time of day and various characteristics of these tourists. Results uncovered show that although a large proportion of our tracked visitors to Tasmania in 2016 (about one third) visited Richmond, a majority only made short visits either out of Hobart or on the way to or from somewhere else. A low rate of overnight stays was also revealed. Interestingly, the time of day tourists visit Richmond is related to their stated trip purpose. So, for example, those visiting Tasmania to experience wildlife and nature tend to visit at a different time to those motivated by history and heritage or food and wine. Differences were also found between these cohorts in their movement patterns 
throughout the town and in the duration of their stay.

Analysis of this nature allows operators and tourism authorities to create more nuanced marketing, including pursuing beneficial co-marketing opportunities and campaigns. It may also allow operators to better target their offerings according to times that may suit relevant cohorts. Above all, the analysis revealed that Richmond had a 'conversion' challenge and would benefit from developing new strategies to encourage a greater percentage of visitors driving through the historic village to stop and explore more of what the destination has to offer.

\section{4) Dispersal into regions}

The dispersal of tourists out of major cities and into the regions has become a priority for many levels of government as it is seen as a way to distribute the benefits of tourism more equitably and promote regional economic development. In Tasmania, dispersal is articulated as one of five key indicators of growth in the visitor economy (T21, 2015). It is important, then, that dispersal is measured as accurately as possible in order to understand dispersal rates and factors associated with it. Traditionally, dispersal is measured by simply assessing gross numbers of visitor night locations from visitor surveys. The Tourism Tracer team has developed a new technique to calculate dispersal which measures exact distance actually travelled by tourists. This means that dependence on tourists' memory and knowledge is no longer necessary. The method also allows for relationships between dispersal and tourist characteristics to be explored. Most importantly perhaps, the method shows the exact extent of dispersal undertaken, taking into account all movement taken, not just the locations where nights were spent.

\section{Towards sustainability: governance and funding challenges}

The Tourism Tracer project and similar technologies, which aim to both track tourist 
movement and simultaneously collect other important information on participants, are still in their infancy but there is growing recognition of their potential to revolutionise tourism planning and research. Indeed the Tourism Tracer project received an Australian innovation award in 2016 (an iAwards Merit Certificate in the Public Sector \& Governance category) and the technology and methods are now being used to conduct visitor research across Australia and internationally. The fact that the cost of data gathering and analysis has declined significantly as the project moves out of its development and proof-of-concept phases will also contribute to the uptake of the technology. Yet despite the rapid development and growing recognition of the benefits of Tourism Tracer there remain a number of governance and funding challenges which have to be resolved to ensure the sustainable uptake and use of the technology while maximising benefits to the tourism industry and wider community in Tasmania and beyond.

Since its inception the project has been informed by a co-creation philosophy which sought to balance the needs and interests of the tourism industry, government and academic researchers. This collaborative approach required both extensive consultation and engagement as well as balancing the competing needs of research partners. Perhaps the most significant governance challenge associated with the project is establishing a clear understanding of data and analysis which can be made publically available through a combination of government, university and general industry funding and bespoke, proprietary analysis which can be made available to clients on a fee for service basis.

It has always been understood that the results of this research with its many benefits as described above, should be publically available for all interested parties. The team's commitment to do this is embodied in the free, online and universally accessible Tourism Tracer Tasmania Dashboard. Clearly too, the fact that the collected data has a wide range of applications means there is a clear rationale for continued government funding. It is in the 
collection of longitudinal data where the real value lies. Trends and variations over time can be assessed and understood as well as the most up to date information being available at any given point in time.

On top this, however, there are a number of concurrent opportunities which could be offered on a fee for service basis, including requests to undertake discrete data analysis and reporting additional to that which is automatically undertaken on the Tourism Tracer Tasmania Dashboard. This could include, for example, analysis on the use of certain roads or other key pieces of infrastructure. The rationale here, then, is that analysis which only benefits one provider or a narrow industry segment should be fee for service. This business opportunity aligns directly with a push within many universities and research systems towards commercialisation. Yet the desire to provide open data and the longer term impacts that commercialisation will have upon the broader tourism research community is yet to be determined.

\section{Conclusion}

This project has demonstrated that co-creation research design processes are well suited to scenarios that involve technology, and multiple stakeholders such as those from the tourism industry, government and university sectors. Moreover, it has demonstrated that co-created research design processes can result in highly innovative outcomes. In doing so it addresses the question posed by Binkhorst and Dekker (2009) as to what type of research is suitable for a co-creation process.

The Tourism Tracer platform and associated technology has positioned itself in Tasmania as a key piece of tourism planning and development infrastructure, that is capable of delivering highly accurate, real time insights into tourist travel and behaviour. Like most public infrastructure there are significant fixed development, and some recurring, costs which 
must be balanced against the many and varied long term benefits of the platform which can be delivered at a lower cost. When combined with the fact that value of the data provided by the platform increases over time as more longitudinal analysis becomes possible, there is a clear case for longer term industry-wide and/or public funding of the technology. Yet the funding and governance of the program also needs to recognise the fact that there are also opportunities to provide proprietary data and analysis on a fee for service basis. Establishing a clear distinction between the public and commercial elements of the Tourism Tracer project has presented some challenges and demands a transparent and proactive approach to stakeholder engagement combined with commitment to reinvest any surpluses from commercial activities back into the broader platform to supplement the public and industry funding for program. From a research perspective, this project has illustrated that it is now possible to determine the exact movement of tourists through destinations. Further research is needed to extend these insights to understanding dispersal, itinerary choice and the development of models to predict movement. Research in this space will produce tangible benefits for the tourism industry and the broader tourism research community.

In terms of moving forward, it is clear then that the core "business" of Tourism Tracer, that is the Tasmanian tracking project, will continue to require a degree of industry and/or government funding in much the same way as destination advertising or more traditional market research programs have been subsidised. However, given the value of the data produced and the growing demand for customised analysis provided using a fee for service model we are hopeful that the need for wider subsidies will decline over time. What is also clear is that technologies such as Tourism Tracer are revolutionising tourism planning and development and will improve the productivity and sustainability of the sector. 


\section{References}

Aussie Towns. (2017). Richmond, TAS. Aussie Towns. http://www.aussietowns.com.au/town/richmond-tas (accessed March 23, 2018).

Bauder, M. \& Freytag, T. (2015) Visitor mobility in the city and the effects of travel preparation, Tourism Geographies, 17:5, 682-700

Bauder, M., Freytag, T., Gérardot, M. (2014) Exploring tourist mobility in Paris. A combined visitor survey and GPS tracking study. EspacesTemps.net, Objects, 17.02.2014 https://www.espacestemps.net/en/articles/analyser-les-mobilites-touristiques-a-paris-encombinant-enquete-visiteurs-et-gps/ accessed 19 June 2018

Beeco, J.A. \& Hallo, J.C. (2014). GPS Tracking of Visitor Use: Factors Influencing Visitor Spatial Behavior on a Complex Trail System. Journal of Park and Recreation Administration, 32(2): 43-61

Beeco, J.A., Huang, W.-J., Hallo, J.C., Norman, W.C., McGehee, N.G., McGee, J., \& Goetcheus, C. (2013). GPS Tracking of Travel Routes of Wanderers and Planners. Tourism Geographies, 15(3): 551-573

Binkhorst, E. \& Dekker, T. (2009). Agenda for Co-Creation Tourism Experience Research, Journal of Hospitality Marketing \& Management, 18(2-3): 311-327.

Birenboim, A., Anton-Clavé, S., Russo A., \& Shoval, N. (2013). Temporal Activity Patterns of Theme Park Visitors, Tourism Geographies: An International Journal of Tourism, Space, Place and Environment, 15(4): 601-619.

Bueno, M., \& Rameckers, L. (2003). Understanding people in new ways. Personas in context: Forging a stronger link between research and its application in design. Proceedings of the Esomar Conference, Venice.

Czernek, K. (2017). Tourism features as determinants of knowledge transfer in the process of tourist cooperation. Current Issues in Tourism, 20(2), 204-220.

De Cantis, S., Ferrante, M., Kahani, A., \& Shoval, N. (2016). Cruise Passengers' behavior at the destination: Investigation using GPS technology. Tourism Management, 52: 133-150

Department of State Growth. (2015). Investigation of Tourists as Drivers and Motorcycle Riders in Tasmania and Road Safety Interventions. Hobart

Disney, https://disneyworld.disney.go.com/en-eu/faq/my-disney-experience/my-magic-plusprivacy/, accessed 15/6/18

Edwards, D., \& Griffin, T. (2013). Understanding tourists' spatial behaviour: GPS tracking as an aid to sustainable destination management. Journal of Sustainable Tourism: 21(4) 580595.

Freytag, T. \& Bauder, M. (2018) Bottom-up touristification and urban transformations in Paris, Tourism Geographies, 20:3, 443-460

Gretzel, U., Sigala, M., Xiang, Z., and Koo, C. (2015). Smart tourism: foundations and developments. Electronic Markets, 25(1): 179-188. 
Grinberger Y., Shoval, N., \& McKercher, B. (2014). Typologies of Tourists' Time-Space Consumption: A New Approach Using GPS Data and GIS Tools, Tourism Geographies, 16(1): 105-123.

Hall, C.M. (2001). Trends in ocean and coastal tourism: the end of the last frontier? Ocean and Coastal Management, 44:601-618.

Hallo, JC, Beeco, J.A., Goetcheus, C., McGee, J., McGehee, N.G. and Norman, W.C. 2012. GPS as a Method for Assessing Spatial and Temporal Use Distributions of Nature-Based Tourists. Journal of Travel Research, 51(5): 591-606

Hardy, A.L., Hyslop, S., Booth, K., Robards, B., Aryal, J., Gretzel, U., \& Eccleston, R. (2017). Tracking tourists' travel with smartphone-based GPS technology: a methodological discussion. Information Technology \& Tourism, 17(3): 255-274.

Leggatt, P. \& Wilks, J. (2009). Overseas Visitor Deaths 2001-2003. Journal of Travel Medicine, 16(4): 243- 247.

Lew, A., \& McKercher, B. (2006). Modeling Tourist Movements: A Local Destination Analysis. Annals of Tourism Research, 33: 403-423.

McKercher, B., \& Lau, G. (2009). Methodological Considerations when Mapping Tourist Movements Within a Destination. Tourism Analysis, 14(4): 443-455.

McKercher, B., Shoval, N., Ng, E., \& Birenboim, A. (2012). First and Repeat Visitor Behaviour: GPS Tracking and GIS Analysis in Hong Kong. Tourism Geographies, 14(1): 147-161.

Modsching, M., Kramer, R., Hagen, K.T., \& Gretzel, U. (2008) Using location-based tracking data to analyze the movements of city tourists. Information Technology \& Tourism, 10(1): $31-42$.

Nielsen, N.C., Harder, H., Tradisauskas, N. and Blichfeldt, B.S. (2010) Approaches to GPSsurvey of tourist movements within a North Sea island destination. ENTER 2010: Volume 1 Short Papers, https://ertr.tamu.edu/special-section-enter-2010/, accessed 22 June 2018

O'Connor, A, Zerger, A, Itami, B (2005) Geo-temporal tracking and analysis of tourist movement. Mathematics and Computers in Simulation 69 (1/2): 135-150

Parks \& Wildlife Service Tasmania, Tasmanian Wilderness and World Heritage Area, http://www.parks.tas.gov.au/index.aspx?base=391, accessed 25 March 2018

Pettersson, R, Zillinger, M (2011) Time and space in event behavior: Tracking visitors by GPS. Tourism Geographies 13 (1): 1-20

Princess Cruises, https://www.princess.com/ships-and-experience/ocean-medallion/, accessed $15 / 6 / 18$

Scott, N., \& Ding, P. (2008). Management of tourism research knowledge in Australia and China. Current Issues in Tourism, 11(6), 514-528. 
Sedarati, P., Pintassilgo, P. and Santoa, S., (2018). System Dynamics in Tourism Planning and Development. Tourism Planning \& Development, DOI:

10.1080/21568316.2018.1436586

Schaffer, V. (2015). Student mentors: aiding tourism businesses to overcome barriers to social media. Current Issues in Tourism, 18(11): 1022-1031.

Sense-T, Sense-T, http://www.sense-t.org.au/, accessed 27 March, 2018

Shoval, N., McKercher, B., Ng, E., \& Birenboim, A. (2011). Hotel location and tourism activity in cities. Annals of Tourism Research, 38(4): 1594-1612.

Shoval, N., \& Isaacson, M. (2005). A model of travel itineraries: The application of tracking technologies to the study of pedestrian spatial behaviour. The Professional Geographer, 58: $172-183$.

T21. 2015. The Tasmanian Visitor Economy Strategy 2015-2020. Hobart.

T21. 2017. The Tasmanian Visitor Economy Strategy 2015-2020: Progress Report 4 December 2017, Hobart.

Thimm, T., \& Seepold, R. (2016). Past, present and future of tourist tracking. Journal of Tourism Futures, 2(1): 43-55.

Tourism Tasmania. 2016. Tourism Research: Tasmanian Tourism Snapshot- year ending March 2016.

Tourism Tracer. 2017a. GPS tracks of tourists in Tasmania: Initial investigation of driver behaviour on four state roads. Hobart, University of Tasmania.

Tourism Tracer, Tourism Tracer Dashboard, https://tasmania.tourismtracer.com/, accessed 27 March 2018

Tourism Tracer. 2017b. Tourist Tracking Project: Report for Hobart Airport on 2016 Data. Hobart, University of Tasmania.

Tourism Tracer. 2017c. Tourist Tracking Project: Report for Launceston Airport on 2016 Data. Hobart, University of Tasmania.

Tourism Tracer. 2017d. Tourist Tracking Project: Report for the Spirit of Tasmania on 2016 Data. Hobart, University of Tasmania.

Tourism Tracer 2017e. Tourist Tracking Project 2016: Wineglass Bay Track Car Park Analysis. Hobart, University of Tasmania.

United Nations World Tourism Organisation (UNWTO) and Global Tourism Research Centre (GTRC). 2016. Asia Tourism Trends, 2016 Edition. Madrid, World Tourism Organisation.

Walters, G., Burns, P., \& Stettler, J. (2015). Fostering collaboration between academia and the tourism sector. Tourism Planning \& Development, 12(4), 489-494. 
Yun, H., \& Park, M. (2015). Time-Space Movement of Festival Visitors in Rural Areas

Using a Smart Phone Application. Asia Pacific Journal of Tourism Research, 20(11): 12461265 .

Zillinger, M. (2010). Experience Tracking - Evaluating Methods for Studying Experiences in Time and Space. ENTER 2010: Volume 1 Short Papers, https://ertr.tamu.edu/special-sectionenter-2010/, accessed 22 June 2018. 